\title{
A diplomacia brasileira no conselho de segurança da ONU: discussões políticas sobre as operações de paz da ONU no Estado haitiano
}

Wemblley Lucena de Araújo ${ }^{1}$

O Haiti está marcado historicamente por ondas de instabilidades decorrentes das disputas políticas e recorrentes lutas pelo poder do Estado haitiano. Esses elementos levaram as violências que transcenderia o aspecto político e atingiria todos os setores sociais. Assim, as divergências e a negligencia por parte das elites políticas levaram às fragilidades nas instituições do Estado haitiano.

Historicamente, cumpre ressaltar que o processo de independência haitiano teve seu início por volta de 1789, com base nos ideais da Revolução Francesa que aos poucos vinham chegando à Ilha de Hispaníola². Absorvendo esses princípios, essa região enfrentou uma rebelião provocada pelos escravos, liderada pelo ex-escravo Toussaint L'Ouverture, esse movimento desencadeou em significativas transformações na colônia francesa. Nesse contexto, em Janeiro de 1804, Jean-Jacques Dessalines proclamou o Haiti um Estado independente, tornando-o a primeira república negra independente e a segunda república independente das Américas (Cavallaro, 2005, p. 4).

Em 1990, recebendo a maioria dos votos, Jean-Bertrand Aristide foi eleito presidente do Haiti e para conseguir esse feito, Aristide contou com apoio popular, principalmente da população mais pobre, que cansada dos regimes duvalieristas, do autoritarismo e da repressão dos militares, viam no novo presidente a esperança de uma

\footnotetext{
${ }^{1}$ Mestre em Relações Internacionais - Programa de Pós-Graduação em Relações Internacionais - PPGRI Universidade Estadual da Paraíba - UEPB. Membro do Grupo de Pesquisa sobre a Política Externa Brasileira no Conselho de Segurança da ONU no pós-Guerra Fria. E-mail: wemblley@gmail.com.

${ }^{2}$ A Ilha de Hispaníola corresponde ao atual território do Haiti e da República Dominicana.
} 
possível reestruturação da ordem e da política doméstica (Araújo, 2011, p. 21). “A OEA e a ONU haviam colaborado em 1990 na observação das eleições haitianas que deram vitória a Jean Bertrand Aristide pela maioria expressiva de 67\% do eleitorado" (Patriota, 2010, p. 120).

Desse modo, inconformados com os resultados da eleição, os militares organizaram um golpe para inviabilizar a chegada de Aristide ao poder, mas inicialmente falharam. Assim, Aristide assumiu o poder em Fevereiro de 1991, tendo René Préval na qualidade de primeiro ministro (Buss, 2008, p. 30). Nos primeiros meses de seu governo, Aristide tentou se consolidar no comando do Haiti, no entanto, adotando um forte posicionamento político, começou a fechar associações políticas domésticas, impedindo a manifestação da oposição, além disso, muitos dos que tinham o ajudado a se eleger não foram nomeados na sua administração, fato que causou um enorme ressentimento político, Aristide rompeu com oficiais, juízes e com a polícia que a ele próprio tinham o apoiado (Buss, 2008, p. 30).

Em 30 de setembro de 1991, meses depois de tomar posse, Aristide sofreu um golpe militar arquitetado pelo comandante das Forças Armadas do Haiti (Roaul Cédras) e apoiado pela elite econômica, fato que levou o presidente Aristide para o exílio nos EUA (International Crisis Group, 2004, p. 4) . Em face desse cenário, ondas de violências e instabilidades se sucederam no Haiti, incluindo a saída em massa de refugiados, sanções econômicas por meio dos mandatos da OEA e do CSNU, até que a ONU desenvolveu sucessivas missões na tentativa de mediação e, finalmente, não solucionada

\footnotetext{
${ }^{3}$ Organização dos Estados Americanos.

${ }^{4}$ Em face da instabilidade política que se desencadeou no Haiti, os três anos de governo apoiado pelos militares que se seguiram foi caracterizado pelo retorno de repressão patrocinada pelo Estado, com "esquadrões da morte" de direita visando partidários de Aristide em grupos de camponeses, o comércio sindicatos e organizações de base, nessa conjuntura cerca de 3.000 a 5.000 pessoas foram assassinadas (Internacional Crisis Group, 2004, p. 4).
} 
a situação, a intervenção militar multinacional liderada pelos EUA em 1994 para restaurar a democracia e reempossar o presidente Aristide ao poder (Hagman, 2002, p. 2).

Em face daquela atmosfera, a questão haitiana passou a ser amplamente discutida no âmbito da ONU, especificamente se tornando pauta das discussões do CSNU. Assim, a partir da necessidade de promover um ambiente de estabilidade no Haiti, a ONU, através de suas operações de paz, passou a atuar mediante os mandatos aprovados pelo CSNU.

Partindo do entendimento das instabilidades políticas haitianas e da incorporação dessa problemática ao âmbito do CSNU, em seguida, discutir-se-á o posicionamento brasileiro no CSNU diante da questão haitiana ao longo dos mandatos do Brasil no organismo no pós-Guerra Fria. Na primeira seção, discutiremos sobre os mandatos 1993-1994 e 1998-1999, no qual o caso do Haiti passa a fazer parte das discussões do CSNU e há o envolvimento político-diplomático brasileiro frente à questão. Em seguida, tratar-se-á dos biênios 2004-2005 e 2010-2011 nos quais há uma intensificação da PEB em relação ao Haiti devido à sua participação na MINUSTAH, elemento que influenciou diretamente nas posturas adotadas pelo Brasil no CSNU.

\section{O Brasil no CSNU e as operações de paz no Haiti: mandatos 1993-1994 e 1998-1999}

A primeira eleição do Brasil para exercer um mandato no CSNU na qualidade de membro não permanente no pós-Guerra Fria se deu durante o biênio 1993-1994. Neste período, o Brasil foi representado no CSNU pelos embaixadores Henrique Valle, Ronaldo Sardenberg, Celso Amorim e Edmundo Fujita. Naquele mesmo período, os chanceleres Fernando Henrique Cardoso e Celso Amorim exerceram os cargos de Ministro das Relações Exteriores durante o governo Itamar Franco. 
Durante a passagem brasileira pelo CSNU no início do pós-Guerra Fria, o Haiti já havia sido incorporado na agenda temática do organismo. Naquele momento, ocorreu a primeira autorização dada pelo CSNU para que uma força de paz fosse utilizada com a finalidade de "restaurar a democracia" e reconduzir ao cargo o Presidente Jean Bertrand Aristide (Viegas, 2008, p. 22). Além disso, o caso haitiano representou a primeira vez em que os EUA buscaram autorização previa do CSNU para uma intervenção no continente americano (Viegas, 2008, p. 22). A Missão das Nações Unidas no Haiti (UNMIH) foi estabelecida de acordo com a resolução S/RES/867 em 23 de setembro de 1993, estabeleceu:

(...) a criação e envio imediato da Missão das Nações Unidas no Haiti (UNMIH) por um período de seis meses, sujeita à condição de que a operação seja estendida após o prazo mínimo de 75 dias, na qual o Conselho de Segurança realizará um exame com base no relatório do Secretário-Geral que indicará se foram atingidos ou não progressos substanciais concernentes com os acordos Ilha do Governador e dos acordos políticos constantes no Pacto de Nova York ${ }^{5}$ [tradução nossa] (United Nation, 1993, p. 2).

\footnotetext{
${ }^{5}$ O Pacto da Ilha do Governador e os acordos políticos de Nova York se caracterizaram por negociações entre a elite política haitiana e o governo dos Estados Unidos como o propósito de minimizar as divergências políticas haitianas que provocavam a desestabilização do Estado do Haiti, além das ondas de violências domésticas que levaram especialmente a geração de um fluxo aparentemente interminável de refugiados haitianos para os EUA (Morrel1,1993).
} 
Diante dessa resolução, o Brasil foi favorável à criação imediata de uma missão da ONU para a estabilização e controle da crise haitiana, tomando em consideração as ondas de violência ocorridas. Assim, em face daquela situação, o Brasil uniu esforços para a recondução do presidente Aristide ao poder e recomendou ao CSNU que adotasse medidas mais eficazes para atuar rapidamente no exercício da operação em campo (Sardenberg, 1993, p. 22).

Nesse contexto, o Brasil apesar de ter sido favorável ao estabelecimento de uma operação, se opôs na proposta da resolução S/RES/940 (1994), não acompanhando a decisão do Conselho (Resolução 940, aprovada com 12 votos a favor e duas abstenções Brasil e China ${ }^{6}$, estando Ruanda ausente). O Brasil considerou que a autorização dada ao uso da força estava posta de forma precipitada, não refletindo os interesses de grande parte dos Estados da região Latino Americana. A chancelaria brasileira alegou que a ONU estava se afastamento de suas práticas no que tange aos processos de manutenção da paz (VIEGAS, 2008, p. 23).

Em 31 de Julho de 1994, a resolução S/RES/940 (1994) revisou o mandato da UNMIH e autorizou o uso da força estabelecendo que:

(...) nos termos do Capítulo VII da Carta da ONU autoriza os EstadosMembros a formar uma força sob comando e controle unificado e, neste quadro, a utilizar todos os meios necessários para facilitar a retirada do Haiti da liderança militar, conformidade com o Acordo de Governos

\footnotetext{
${ }^{6}$ Além do Brasil, a China se absteve da resolução por considerar que a questão haitiana não poderia ser resolvida por meios militares com a utilização do Capítulo VII. Na visão da chancelaria chinesa tal medida vinha em desencontro às práticas da ONU (United Nations, 1994a, p.10).
} 
Island, o retorno imediato do presidente legitimamente eleito e da restauração das autoridades legítimas de Governo do Haiti, bem como estabelecer e manter um ambiente seguro e estável assim como estabelecido nos acordos da Ilha do Governador, entendendo que o custo de implementar e executar esta operação temporária serão custeadas pelos Estados-Membros que dela participam [tradução e destaque nosso] (United Nations, 1994b, p. 2).

A resolução S/RES/940 (1994) levou pela primeira vez na história das discussões do CSNU ao debate sobre o uso da força (em virtude da utilização do Capítulo VII) em relação a um Estado do Hemisfério Ocidental. No âmbito do CSNU, o embaixador brasileiro Sardenberg argumentou que:

No Brasil, a Constituição prevê, em seu artigo 4, os princípios que orientam e condicionam a conduta das nossas relações internacionais. Entre estes, contam os princípios em observância aos direitos humanos, autodeterminação dos povos, não intervenção, igualdade entre os Estados e solução pacífica de controvérsias. A Carta da Organização dos Estados Americanos (OEA) claramente expressa que os países da região aderem à democracia representativa, indicado no Artigo 2.(b) da Organização que expressa o propósito fundamental de "promover e consolidar a democracia representativa com o devido respeito ao princípio da não intervenção" [tradução nossa] (Sardenberg, 1994a, p. 9). 
Partindo desse posicionamento, o Brasil fundamentou sua postura com base na utilização dos princípios tradicionais que regem as relações internacionais presentes na Constituição brasileira e são expressos em tratados internacionais como a Carta da OEA em que apontam para a não intervenção e a resolução de controvérsia por meios pacíficos. Nessa linha de argumentação, prosseguiu o embaixador Sardenberg:

(...) o curto período de tempo não nos deixaram esclarecidos o suficiente para uma plena consideração das vastas consequências, complexa e imprevisível, na situação do Haiti. Os riscos envolvidos não só para o povo do Haiti, mas também por parte da comunidade internacional, não devem ser subestimados. Pela mesma razão, a defesa da democracia deve estar sempre coerente com os princípios que regem as relações entre os Estados e não inclui o uso da força nas condições nesse momento contempladas. Assim, as condições aqui postas significam um distanciamento inquietante dos princípios e práticas costumeiras adotadas pela Organização das Nações Unidas para a manutenção da paz [tradução nossa] (Sardenberg, 1994a, p. 9)7.

7 Naquela ocasião, a China se absteve na resolução S/RES/940 (1994) por não concordar com as medidas
vinculativas ao Capítulo VII da Carta da ONU para resolver o problema do Haiti. Assim, a delegação chinesa
ressaltou que a solução de um problema como o Haiti por meios militares não seria consistente com os princípios
consagrados na Carta da ONU (Li Zhaoxing, 1994, p. 10). A Rússia votou a favor da resolução S/RES/940 (1994) ao
considerar que o CSNU não poderia mais tolerar as constantes violações de direitos humanos no Haiti. De acordo
com a delegação russa a resolução foi um passo difícil, porém necessário para acabar com a crise prolongada no
Haiti, e assim, garantir a implementação das medidas adotadas pelo CSNU. Ao votar a favor nesta resolução, a
Rússia levou em conta o fato de que a resolução tem o apoio do presidente Jean-Bertrand Aristide (Vorontsov, 1994,
p. 24). Os Estados Unidos votaram a favor da resolução S/RES/940 (1994) ao considerar sua aprovação como
histórica e defendeu que a autorização dada aos Estados-membros a utilizar todos os meios necessários apoiaria na
estabilização da autoridade legítima e constitucional Haiti. Ao fazê-lo, culminou no esforço do Conselho em
devolver ao povo haitiano a democracia e promover o Estado de Direito (Albright, 1994, p. 12). A França votou a
favor da resolução S/RES/940 (1994) ao compreender que a comunidade internacional foi paciente ao máximo ao
acreditar no poder do diálogo e da negociação, mas estava errada. Desse modo, o uso do Capitulo VII da Carta para
uma ação militar multinacional, não foi uma decisão tomada de forma precipitada, ou seja, a decisão foi adotada de
forma pensada e coerente com a situação (Ladsous, 1994, p. 14). A delegação do Reino Unido votou a favor da

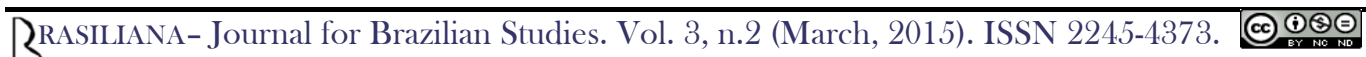


Desta forma, o Brasil sinalizou que houve uma mudança nas discussões referentes à questão: se antes havia uma força de manutenção da paz para a reestabilização do Haiti; posteriormente, estava se tratando de uma força de imposição da paz (Sardenberg, 1994a, p. 8). Com base nesse argumento, o Brasil se absteve da resolução S/RES/940 (1994). Segundo Uziel (2010, p. 159), a postura brasileira não foi vista pelos EUA e pelos demais membros do CSNU como uma ação inconsequente, ou seja, ausente de critérios analíticos; ao contrário, ficou evidente para o Brasil que se tratava da defesa do princípio de que a Organização não poderia legitimar a sua ocupação no Estado haitiano.

Reafirmando a postura adotada na resolução S/RES/940 (1994), o Brasil se absteve nas resoluções seguintes que tratariam da temática haitiana S/RES/944 (1994), S/RES/949 (1994) e S/RES/964 (1994). Ambas as resoluções representavam a ampliação dos esforços da UNMIH para sua atuação em campo e estavam amparadas no Capítulo VII da Carta da ONU. A respeito dessa conduta, o embaixador Sardenberg endossou que:

Desde o começo da crise no Haiti, o Brasil tem apoiado constantemente os esforços diplomáticos desenvolvidos para restaurar a democracia de um país irmão, membro do grupo de Estados da América Latina e Caribe. Nosso objetivo tem sido claro: o restabelecimento do governo constitucional, com o regresso ao poder do presidente Jean-Bertrand Aristide por meios pacíficos [tradução e destaque nosso] (Sardenberg, 1994b, p. 4).

resolução S/RES/940 (1994) ao reconhecer as intensivas atividades desempenhadas pela ONU a fim de solucionar a situação por meios pacíficos, não obtendo êxito, a aplicação de mediadas mais enérgicas tornaram-se necessárias em função da insegurança desencadeada no Haiti (Gomersall, 1994, p. 18). 
Desse modo, diante das resoluções mencionadas, o Brasil destacou que apoiaria a ampliação dos esforços para a UNMIH e de seus recursos materiais. No entanto, do ponto de vista político, o Brasil não poderia retroagir em sua decisão inicial no que se refere a "utilização de todos os meios necessários", ou seja, o uso da força. No entanto, a delegação brasileira deixou evidente que estaria disposta a continuar apoiando na promoção e reabilitação econômica e social do Estado haitiano (Sardenberg, 1994b, p. 4).

No governo do presidente Fernando Henrique Cardoso, no que concerne ao segundo mandato do Brasil no CSNU no período pós-Guerra Fria (biênio 1998-1999), o Ministro das Relações Exteriores fora o chanceler Luiz Felipe Palmeira Lampreia, que inclusive representou o Brasil durante algumas sessões no CSNU, assim como Celso Amorim, Enio Cordeiro e Henrique Valle.

Durante esse período, por iniciativa do Brasil, a resolução S/RES/1212 (1998) encorajou a atuação do Conselho Econômico e Social das Nações Unidas (ECOSOC) a desenvolver iniciativas para o reestabelecimento econômico e social, objetivando promover um programa de apoio de longo prazo a fim de atender as necessidades do Haiti nos setores econômico e de desenvolvimento social (Fonseca Jr., 2002, p. 136). Partindo desse posicionamento, Amorim (1998, p. 5) alegou que além do Haiti, outros Estados em situações pós-conflito poderiam se beneficiar da ênfase dada ao ECOSOC e que tal mecanismo deveria ser aplicado a outras esferas, especialmente aquelas que envolvem os processos de consolidação da paz como etapa posterior ao conflito ${ }^{8}$. Dessa forma, Amorim reiterou que:

\footnotetext{
${ }^{8}$ O Brasil foi um dos cinco membros do Grupo "ad hoc" que preparavam recomendações que eram aprovadas pela resolução 1999/11 do ECOSOC, na qual se constatava que o maior desafio enfrentado pelo Haiti estava nos campos da democracia e reconstrução da economia (Fonseca Jr., 2002, p. 137).
} 
(...) apesar de avanços importantes alcançados pela MIPONUH desde seu estabelecimento há um ano, a consolidação da paz no Haiti não pode ser considerada uma conquistada em definitivo. De fato, a força policial haitiana ainda não é auto-sustentável e encontra-se diante de novos desafios relacionados à segurança. Com efeito, a reforma judicial, crucial à consolidação da democracia, tem sofrido atrasos lamentáveis. O impasse político que se observa desde junho de 1997 continua a minar as instituições nacionais e a dificultar a implementação das reformas direcionadas à solução dos sérios problemas econômicos e sociais que o país enfrenta. Neste sentido, entendemos que a extensão do mandato da MIPONUH como uma estratégia preventiva tem que incluir outros aspectos, especialmente a assistência econômica para a reconstrução e o desenvolvimento do Haiti [tradução e destaques nosso] (Amorim, 1998, p. 5).

De acordo com o argumento de Amorim (1998), havia naquele momento a necessidade de ampliação do mandato da Missão de Polícia das Nações Unidas no Haiti $(\mathrm{MIPONUH})^{9}$ tanto do ponto de vista temporal quanto dimensional. Temporal, na medida em que se concluísse o processo de transição; e dimensional, no que se refere aos diversos aspectos que envolvem a reestabilização da economia, reconstrução institucional e desenvolvimento social do povo haitiano o que exige diversas frentes de atuação.

\footnotetext{
${ }^{9}$ Diante do pedido do Presidente da República do Haiti, decide estabelecer até 30 de novembro de 1998, uma Missão de Polícia Civil das Nações Unidas no Haiti (MIPONUH), que será composta por um máximo de 300 policiais civis, com limitado e um único período de um ano, que termina 30 de novembro mandato 1998, a fim de continuar a ajudar o Governo do Haiti, apoiando-o e contribuindo para a profissionalização da Polícia Nacional do Haiti (PNH) e incluindo o monitoramento desta em campo (United Nations, 1997, p. 2).
} 
Para Fonseca Jr. (2002, p. 137), os pronunciamentos do Brasil no CSNU além de enfatizarem a renovação do mandato da MIPONUH, colocou em destaque a necessidade de uma missão de caráter multidimensional, de modo que esta atendesse as premências dos setores diagnosticados como críticos, aos quais deveriam envolver os campos dos direitos humanos, justiça, sistema eleitoral, desenvolvimento econômico e social, além da segurança doméstica por meio do treinamento da Polícia Nacional Haitiana (PNH).

Atendendo aos vários pontos destacados pelo Brasil, o país foi copatrocinador do projeto de resolução S/RES/1277 de 30 de Novembro de 199910, na qual defendeu a ampliação do mandato da MIPONUH com o intuito de proporcionar o tempo necessário para o processo de transição, que deveria dar lugar a uma Missão Civil Internacional de Apoio ao Haiti e que possibilitaria o CSNU transferir a competência da questão à AGNU no tocante à manutenção da assistência ao Estado haitiano (Cordeiro, 1999, p. 5).

Para o Brasil, a questão haitiana representou uma oportunidade inovadora de promover uma maior integração entre os organismos onusianos, neste caso: a AGNU, o ECOSOC e o CSNU, organismos que deveriam estar inseridos de forma coordenada, proporcionando uma transição coerente de uma operação de manutenção da paz para um processo de consolidação da paz em Estados em período pós-conflito (Fonseca Jr., 2002, p. 137).

Ao considerar a eclosão da crise enfrentada pelo Haiti em 2004, o CSNU autorizou uma operação com características multidimensionais com o intuito de dar

\footnotetext{
${ }^{10}$ A resolução S/RES/1277 (1999) decidiu manter as funções da MIPONUH em vigência com a finalidade de garantir uma transição por etapas, ou seja, a MIPONUH seria retirada gradativamente e suas competências iriam sendo transferidas a uma Missão Civil Internacional de Apoio ao Haiti (MICAH) que se estabeleceria em 15 de Março de 2000 (United Nations, 1999a, p. 2).
} 
continuidade ao processo de reestruturação do Estado haitiano. Esse momento se caracterizou numa oportunidade do Brasil contribuir significativamente com tropas e discutir mais enfaticamente sua posição no CSNU frente à problemática haitiana.

\section{O Brasil no CSNU nos mandatos 2004-2005 e 2010-2011: discussões sobre a MINUSTAH}

Durante as eleições presidenciais e parlamentares de 2000, Aristide e seu partido Fanmi Lavalas reivindicaram a vitória quando apenas $10 \%$ do eleitorado tinham votado, fato que levou a oposição a contestar os resultados acusando o governo de fraude no pleito (United Nations, 2004a, p. 3). Esse fato iniciou uma revolta armada, formada principalmente por ex-membros das Forças Armadas, grupos paramilitares que passaram a intimidar Aristide e a provocar diversos crimes na tentativa de desestabilizar o governo, nesse período uma série de violações de direitos humanos passaram a ser recorrentes no Haiti.

Diante dessa conjuntura, a oposição passou a ser objeto de perseguições por parte de setores politizados da PNH. A CARICOM se ofereceu como mediadora dos impasses políticos, posteriormente França, EUA, OEA e Canadá nesse canal de mediação (United Nations, 2004a, p. 3).

No início de Fevereiro de 2004 eclodiu um conflito armado na cidade de Gonaives que gradativamente foi se alastrando para outras cidades até chegar a capital de Port-au-Prince. Em face dessa situação, em 26 de Fevereiro de 2004, o CSNU se reuniu em sua $4917^{a}$ sessão para discutir a situação haitiana. Naquela ocasião, o Brasil assinalou que:

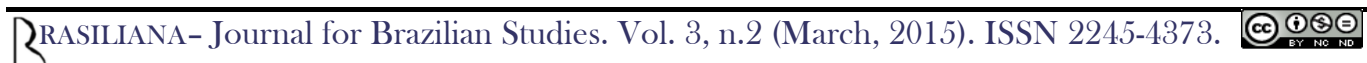


Na busca de uma solução política para a grave crise no Haiti, o Brasil apreciou os esforços que a CARICOM e OEA estiveram desempenhando. A delegação brasileira advogou que todos os atores demonstrem as suas vontades de estabelecer um diálogo eficaz e construtivo e renunciem a todos os atos de violência que tentam comprometer a própria condução do diálogo político no Haiti. Dessa forma, o Brasil pediu a todas as partes a prestar toda a assistência possível nos esforços destinado a estabelecer a paz no Haiti [tradução nossa] (Valle, 2004a, p. 2) ${ }^{11}$.

No entanto, embora ainda acreditava-se que fosse possível uma negociação política por meios pacíficos, o presidente Aristide não resistiu às pressões internas e abandonou o Haiti nas primeiras horas do dia 29 de Fevereiro de 2004; imediatamente, o então

\footnotetext{
${ }^{11}$ Naquela ocasião, a França condenou as profundas ondas de violências e violações dos direitos humanos no Haiti, assim, sinalizou que a comunidade internacional, incluindo o apoio das organizações regionais, como a CARICOM e a OEA poderiam cumprir um papel essencial na estabilização do Estado haitiano (La Sablière, 2004, p. 15). Os Estados Unidos demonstraram preocupação com a crise política no Haiti, defendendo medidas para cessar o uso de violência e apelo a todos os atores políticos para promover o dialogo a fim de alcançar uma solução constitucional e política sustentável. Assim, sinalizou que iriam apoiar os esforços para implantar uma força internacional para apoiar o desenvolvimento político e constitucional do Estado haitiano (Negroponte, 2004, p. 15). A China se demonstrou preocupada com o grande número de vítimas resultantes da deterioração continuada da situação. $\mathrm{Na}$ ocasião, a delegação chinesa parabenizou a OEA, a CARICON e outros agentes que pressionaram todas as partes Haiti a sair do impasse atual, além disso, concordou em continuar a desempenhar um papel ativo. Pediu à comunidade internacional a prestar assistência humanitária ao povo do Haiti e alegou que participaria de esforços da comunidade internacional para mitigar a crise, e contribuir para o estabelecimento da paz, estabilidade e desenvolvimento do Haiti (Wang Guangya, 2004, p. 19). A Rússia condenou os constantes atos de violência ocorridos no Haiti desde o início de fevereiro de 2004. Diante daquela situação, a delegação russa exigiu chamar todas as forças da comunidade internacional para cessar a violência e empreender um diálogo pacífico que possam superar as diferenças e problemas existentes e manter as bases democráticas e constitucionais do país (Konuzin, 2004, p. 9). O Reino Unido ressaltou que ainda seria possível resolver a crise política de forma pacífica através das negociações e recomendou que todas as partes no Haiti contribuíssem para promover a restauração da ordem pública, priorizando o bem-estar da população civil em conformidade com os direitos humanos. Nesse sentido, o Reino Unido esteve disposto a estudar cuidadosamente as propostas da comunidade internacional para ajudar a estabilizar a situação (Thomson, 2004, p. $10)$.
}

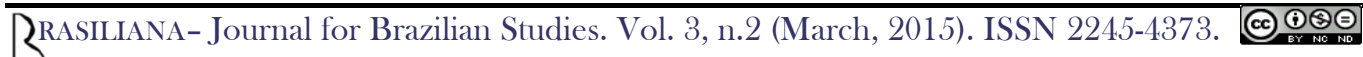


Primeiro Ministro Yvon Neptune leu a carta de demissão deixada por Aristide (United Nations, 2004a, p. 3). Em seguida, Boniface Alexandre, presidente da Suprema Corte, assumiu o cargo de presidente interino em conformidade com as leis constitucionais haitianas sobre sucessão. Logo depois, o representante permanente do Haiti apresentou à ONU a solicitação de assistência ao governo interino, na qual autorizava a entrada de tropas internacionais no Haiti (United Nations, 2004a, p. 3).

Em resposta a esse pedido, o CSNU autorizou por unanimidade a Força Multinacional Internacional (FMI) de acordo com a Resolução S/RES/152912 de 29 de Fevereiro de 2004, e em conformidade com o Capítulo VII da Carta da ONU, tinha por objetivo principal “[...] apoiar a continuação de um processo pacífico e constitucional, mantendo um ambiente seguro e estável no Haiti" (United Nations, 2004b, p. 2) ${ }^{13}$. Desse modo, o CSNU autorizou a FMI para agir de forma imediata no Haiti e sinalizou que estabeleceria posteriormente uma missão de paz capaz de prosseguir em continuidade com o processo de estabilização do Estado haitiano.

Durante as discussões para o estabelecimento da MINUSTAH no Haiti, o Brasil cumpria seu nono mandato-biênio (2004-2005) no CSNU. Nesse período, Celso Amorim

\footnotetext{
${ }^{12}$ Votaram a favor da resolução S/RES/1529 os seguintes Estados: Argélia, Angola, Benin, Brasil, Chile, China, França, Alemanha, Paquistão, Filipinas, Romênia, Federação Russa, Espanha, Reino Unido, Estados Unidos da América (United Nations, 2004b, p. 3).

13 Além disso, a resolução S/RES/1529 estabeleceu que a FMI tivesse por objetivos: a) Contribuir para o desenvolvimento de um ambiente de segurança e estabilidade na capital do Haiti e no resto do país, conforme o pedido de assistência internacional em apoio ao presidente no processo político constitucional em curso no Haiti; $b$ ) Facilitar a prestação de assistência humanitária e acesso dos trabalhadores ajuda internacional ao povo haitiano em necessidade; c) Facilitar a prestação de assistência internacional para a polícia e a Guarda Costeira do Haiti a fim de manter a segurança e a ordem pública, e promover e proteger os direitos humanos; d) Apoiar a criação das condições necessárias para as organizações internacionais e regionais, em especial a ONU e a OEA na ajuda ao povo do Haiti; e) Coordenar as atividades, conforme a necessidade, com a Missão Especial da Organização dos Estados Americanos e do Assessor Especial para o Haiti na ONU e evitar uma maior deterioração da situação humanitária (United Nations, 2004b, p. 2).
} 
exerceu o cargo de Ministro das Relações Exteriores representando também o Brasil em algumas sessões no CSNU além dos embaixadores Henrique Valle, Tarrise da Fontoura e Ronaldo Mota Sardenberg.

Diante dessa conjuntura, o Brasil defendeu que a resolução posterior deveria estabelecer o envio da força multidimensional, porém com prazo específico para o seu desligamento e o estabelecimento datado de uma missão de paz no território haitiano (Viegas, 2008, p. 24). O Brasil não esteve presente na FMI, mas na qualidade de membro eletivo do CSNU votou a favor da resolução S/RES/1529 (2004) que autorizou a entrada da missão em território haitiano e se comprometeu que daria contribuições substantivas no envio da futura operação onusiana, além de se indicar como líder do componente militar da missão (Uziel, 2010, p. 95).

Posteriormente, o Brasil se empenhou de forma favorável a Missão das Nações Unidas para a Estabilização no Haiti - MINUSTAH. A missão foi estabelecida através da resolução S/RES/1542 em 30 de Abril de 2004, a pedido do Presidente interino do Haiti Boniface Alexander. Seu objetivo residia naquele momento, em auxiliar o país caribenho a superar uma crise que já não só envolvia a dimensão política, como interceptava todos os outros setores sociais. De acordo com a resolução S/RES/1542 (2004), o CSNU aprovou por unanimidade ${ }^{14}$ :

(...) a Missão das Nações Unidas para Estabilização no Haiti MINUSTAH, como uma força de estabilização solicitada por meio da

\footnotetext{
14 Votaram a favor da resolução S/RES/1542 (2004): Argélia, Angola, Benin, Brasil, Chile, China, França, Alemanha, Paquistão, Filipinas, Romênia, Federação Russa, Espanha, Reino Unido e Estados Unidos da América (United Nations, 2004e, p. 2).
} 
resolução 1529 (2004), por um período inicial de seis meses com a intenção de renová-la por novos períodos e apela para que a autoridade da FMI seja transferida à MINUSTAH em 1ํ de Junho de 2004 [tradução nossa] (United Nations, 2004d, p. 2).

Para o Brasil, a MINUSTAH foi estabelecida com intuito de reconstrução de longo prazo do Estado haitiano enfatizando desse modo, as necessidades de assegurar os diversos aspectos relacionados à ordem e à segurança doméstica haitiana. Em Novembro de 2004, o Brasil considerou que, na medida em que progredia a situação no Haiti, a MINUSTAH necessitava de um mandato mais específico e concreto do que o estabelecido por meio da resolução S/RES/1542 (2004) e que este, deveria indicar soluções adequadas que permitisse dar respostas às ameaças à segurança no Haiti, aplicando assim, medidas mais eficientes com a finalidade de alcançar uma melhoria emergencial nas condições de vida do povo haitiano (Valle, 2004a, p. 2). Com base na posição brasileira, mesmo em evidencia que o setor da segurança ainda se configurava como uma questão-chave para o reestabelecimento da ordem doméstica, outros setores também deveriam ser levados em consideração. Nesse sentido, o Brasil ressaltou que:

(...) a segurança continua a ser fundamental para a estabilidade do Haiti. No entanto, uma solução sustentável para os muitos desafios enfrentados pelo país certamente iria além da dimensão da segurança. Uma vez que a segurança e outros aspectos importantes da crise haitiana estão inter-relacionados. Nesse sentido, nos parece essencial que os avanços nos âmbitos das necessidades para a reconciliação política, reconstrução econômica e da melhoria social devem ocorrer em 
paralelo com os esforços que estão sendo feitos na área de segurança [tradução nossa] (Valle, 2004a, p. 2).

Evidenciando esse aspecto, o Brasil sinalizou para a necessidade de adequação dos mandatos estabelecidos para MINUSTAH às necessidades que estavam sendo geradas em decorrência das novas demandas do contexto local. De acordo com a posição brasileira, o CSNU deveria adotar medidas mais firmes, inserindo no mandato da MINUSTAH as características de natureza multidimensionais, a fim de abranger as diversas áreas de reconstrução e reestabelecimento da ordem política, econômica e social no Estado haitiano (Valle, 2004a, p. 2).

Para o Brasil, é nesse contexto que a comunidade internacional e as instituições financeiras deveriam reforçar suas assistências com o intuito de promover e melhorar a gestão dos projetos em desenvolvimento e contribuir para a solução de qualquer lacuna que pudesse prejudicar o processo de estabilização do Haiti (Valle, 2004a, p. 3).

No início de 2005, em discurso proferido na Reunião Especial do Conselho de Segurança da ONU sobre o Haiti, o chanceler Celso Amorim, destacou alguns dos progressos alcançados pela missão durante os primeiros meses de sua atuação em campo. Para Amorim:

(...) os progressos alcançados até então demonstraram o quanto eram infundadas as análises pessimistas sobre a capacidade da MINUSTAH em matéria de segurança. Os primeiros meses foram marcados por atrasos na chegada do contingente planejado, pela falta de diálogo político e pela deterioração da economia, agravada por desastres naturais. No entanto, foram alcançados progressos na medida em que o 
número de soldados e policiais aumentava em campo e que os primeiros projetos de reconstrução começavam a ser implementados. Devemos o nosso reconhecimento a MINUSTAH pelas provas que deu da sua capacidade de reduzir a violência no cumprimento do seu mandato, de acordo com a Resolução 1542 (Amorim, 2005a, p. 10).

De acordo com o argumento de Amorim (2005a, p. 10), mesmo considerando as dificuldades de ordem organizacional enfrentadas pela operação em campo, foi notória a minimização dos efeitos causados pela violência doméstica. Sendo assim, o diagnóstico inicial destacado pelo Brasil foi de que a missão inicialmente logrou relativos êxitos, especialmente no que concerne a diminuição dos conflitos sociais no âmbito doméstico.

Para Amorim (2005a, p. 9), o bom desempenho da MINUSTAH foi reflexo da concentração das estratégias em três eixos centrais: a manutenção da ordem e da segurança doméstica, a facilitação e abertura para o diálogo político, a fim de estabelecer a reconciliação nacional, e as ênfases voltadas para a promoção do desenvolvimento econômico e social.

Dessa forma, com base no argumento brasileiro, as medidas adotadas pela MINUSTAH deveriam estar inseridas numa estratégia de longo prazo, com a participação da assistência da comunidade internacional, principalmente com a contribuição dos países da região latino-americana, na medida em que a estabilidade do Haiti passasse a ser percebida como indissociável dos países da região (Amorim, 2005a, p.10). No que tange aos aspectos de cooperação entre instituições internacionais, o Brasil ressaltou a necessidade de inserir mecanismos facilitadores para a manutenção de 
diálogos entre a MINUSTAH e a Comunidade e Mercado Comum do Caribe CARICOM.

No período 2006-2009, a MINUSTAH prosseguiu suas atividades ao processo de reconstrução político-institucional no Estado haitiano, direcionando-se a abertura e facilitação dos diálogos políticos; na assistência, organização e execução das eleições parlamentares e presidenciais no Haiti, no desenvolvimento e profissionalização da PNH e na redução da criminalidade e das violações aos direitos humanos do povo haitiano.

Durante o biênio 2010-2011, o Brasil cumpriu seu décimo mandato eletivo no CSNU. Em 2010, durante o último ano do governo Lula, o chanceler Celso Amorim ainda estava ocupando o cargo de Ministro das Relações Exteriores; já em 2011, no primeiro ano do governo Dilma, o mesmo cargo foi ocupado pelo chanceler Antônio Patriota. No âmbito do CSNU, o Brasil foi representado durante o biênio 2010-2011 por Regina Maria Cordeiro Dunlop, Maria Luiza Viotti, Antônio Ferreira Simões, Norberto Moretti e Vera Lúcia Crivano Machado.

As discussões no CSNU sobre as operações de paz no Haiti durante o biênio 2010-2011 foram moldadas pelo advento do terremoto que abalou o Haiti. No dia 12 de Janeiro de 2010, o Haiti foi abalado por um terremoto de magnitude 7,0 na escala Richter que afetou gravemente a capacidade do Estado haitiano (United Nations, 2010). Naquele momento, os esforços brasileiros se concentraram nos campos político, econômico e social, bem como na reconstrução da capacidade institucional haitiana (Viotti, 2010a, p. 7). Com base nesse aspecto, a estabilidade política tornou-se elemento crucial para a estabilização do Haiti, bem como a participação de todos os agentes e agências envolvidos no processo de reconstrução no longo prazo. 
De fato, os discursos do Brasil durante o biênio 2010-2011, concentraram-se na problemática de se estabelecer critérios e estratégias calcadas no novo desafio enfrentado pelo Haiti no momento pós-terremoto. Para o Brasil, as conferências e doações para o restabelecimento haitiano deveria incorporar estratégias que refletissem as reais necessidades institucionais e sociais enfrentadas pelos haitianos.

Desta forma, o papel da MINUSTAH se configurou como mecanismo fundamental para a estabilização do Haiti, e por meio desta missão a promoção do desenvolvimento social e econômico haitiano. Nesse sentido, a embaixadora brasileira Viotti ressaltou que:

(...) a MINUSTAH continuou sendo um mecanismo fundamental nos esforços e estratégias internacionais para a reconstrução do Haiti. Seu papel tornou-se único enquanto apoiador da estabilidade da segurança e do Estado de direito (Viotti, 2010a, p. 8).

No entanto, a ausência de recursos suficientes para o prosseguimento da operação em campo gerou dificuldades para a execução das estratégias traçadas, elemento que a delegação brasileira constantemente enfatizou no âmbito do CSNU.

Nesse contexto, o Brasil defendeu que as atividades da MINUSTAH deveriam se direcionar para a promoção do diálogo entre as autoridades locais, na preparação e realização de eleições e que estas mereceriam ser calcadas em padrões livres e democráticos (Viotti, 2010a, p. 8). Em observância a esse aspecto, há de se considerar que o terremoto não suprimiu todos os trabalhos na esfera da estabilização alcançados no Haiti, mas apareceram novos obstáculos a serem enfrentados. Destarte, o Brasil ainda frisou a importância do processo de coordenação da MINUSTAH na organização das futuras eleições em cooperação com outros parceiros mediante a interconexão de 
estratégias com outros organismos e agências internacionais, a exemplo da OEA (United Nations, 2010).

No plano da segurança, o Brasil defendeu que a MINUSTAH se concentrasse no apoio à PNH e em suas atividades relativas à manutenção da segurança e no desenvolvimento da capacidade da instituição haitiana, sendo favorável às recomendações do Secretário Geral no que se refere à ampliação do contingente policial (Viotti, 2010a, p. 8). Esse seria um aspecto, que segundo a posição brasileira, contribuiria para o papel MINUSTAH no processo de reestabilização e controle da ordem doméstica, além de facilitar na execução das estratégias nos demais setores contribuindo assim, para a construção de um ambiente estável em longo prazo.

Em setembro de 2010, o Brasil declarou no CSNU que a MINUSTAH deveria estabelecer mecanismos de auxílio aos deslocados internos vitimados pelo terremoto que se tornaram a população mais vulnerável do Haiti. Assim, esses mecanismos atuariam principalmente em atividades contra as ocorrências de violências sexuais e de gênero, por meio da promoção de programas específicos com o intuito de reduzir a insegurança nas principais comunidades acometidas por esse tipo de violência (Viotti, 2010b, p. 8).

Nesse mesmo período, o Brasil ressaltou que mesmo levando em consideração certos avanços a MINUSTAH precisaria esforçar-se para acelerar o processo de reconstrução com base na adoção de medidas estratégia tais como: avançar nos processos de remoção dos escombros provocados pelo terremoto, realizar a identificação e preparação dos terrenos para o reassentamento e aplicação imediata de projetos destinados à reconstrução (Viotti, 2010b, p. 8). Neste sentido, em janeiro de 2011, um ano após o desastre provocado pelo terremoto, a Embaixadora Maria Luiza Viotti, assinalou que: 
(...) o papel da MINUSTAH foi fundamental nos esforços para a realização do processo eleitoral e nos seus constantes contatos com as autoridades locais, em particular com a Polícia Nacional do Haiti que ficou incumbida de garantir um ambiente seguro nas circunstâncias difíceis decorrentes dos anúncios dos resultados preliminares do primeiro turno das eleições [tradução nossa] (Viotti, 2011a, p. 9).

Para o Brasil, estabelecer um ambiente seguro no momento pós-eleições seria um elemento crucial para a manutenção da ordem e o bom prosseguimento do processo democrático. No mesmo sentido que, eleger um novo presidente e instaurar um novo parlamento representaria naquele momento, um dos aspectos fundamentais para solidificar a democracia haitiana (Viotti, 2011a, p. 9).

No entanto, as contribuições realizadas pelos Estados continuavam sendo insuficientes para levar adiante esse processo, fato que exigiu maior comprometimento em termos de recursos por parte dos Estados doadores (Viotti, 2011a, p. 9). Nesse viés, há de se considerar que as contribuições brasileiras se deram tanto no plano multilateral quanto no plano bilateral. No âmbito do CSNU, o Brasil ressaltou que:

(...) no nível multilateral, o Brasil contribui com tropas para a Missão de Estabilização das Nações Unidas no Haiti (MINUSTAH) e como responsável pela direção de seu componente militar está empenhado na interação harmoniosa e construtiva de nossos homens e mulheres de uniforme para promover o desenvolvimento da população local. (...) os haitianos frequentemente se referem às tropas brasileiras como "bon bagay" - expressão que em crioulo significa "boas pessoas". Esta 
relação de proximidade, na qual a implementação de projetos de rápido impacto é uma contribuição chave, tem consequências importantes no tocante à execução do mandato da MINUSTAH e na manutenção da segurança e geração de um ambiente estável. No nível bilateral, o Brasil ofereceu de formas de cooperação consistentes ao Haiti, em diferentes modalidades: agricultura, saúde, energia, criação de empregos, construção institucional, entre outras [tradução e destaque nosso] (Simões, 2011, p. 12).

No que se refere à natureza multidimensional, houve uma relevante ênfase do Brasil na interligação e incorporação dos elementos de promoção do desenvolvimento aos da segurança internacional nos mecanismos de atuação da MINUSTAH. Nesse sentido, o Brasil:

(...) desde o início, defendeu uma abordagem verdadeiramente multidisciplinar para a MINUSTAH, por meio de ações paralelas com o objetivo de promover a segurança, a reconciliação e o desenvolvimento. A estabilidade e segurança são fundamentais para atrair investimentos e sustentar o crescimento. Em suma, a promoção do Estado de Direito, de progressos econômicos e sociais reforçam mutuamente partes de nossos trabalhos no Haiti [tradução e destaque nosso] (Simões, 2011, p. 12).

A posição brasileira destacou que a adoção de uma abordagem multidisciplinar ou multidimensional para a MINUSTAH dependia naquele momento, da capacidade do CSNU de estabelecer mecanismos que permitisse a coordenação entre todos os níveis da 
missão, principalmente entre a MINUSTAH e a Comissão Interina para a Reconstrução no Haiti (Simões, 2011, p. 13). Partindo desse entendimento, o bom gerenciamento e a coordenação desses níveis ditaria o desempenho no trabalho dos diversos setores em campo.

Em setembro de 2011, o Brasil mais uma vez destacou no CSNU o fundamental papel da MINUSTAH nos processos de segurança e desenvolvimento social e econômico do Haiti. Segundo a representante brasileira no CSNU Maria Luiza Viotti:

\section{(...) a experiência da Missão de Estabilização das Nações no Haiti} (MINUSTAH) nos deu muitos exemplos de vantagens de se lidar com a segurança e o desenvolvimento como desafios interligados. Os fatos recentes têm corroborado com esse ponto de vista. Em julho, como mencionado pelo embaixador Fernandez Amunátegui, a MINUSTAH conduziu Operação Phoenix em áreas pobres de Port-au-Prince com o intuito de conter o ressurgimento das gangues e da atividade criminal. Graças à operação, reduziu os índices de criminalidade e aumentou o nível de assistência social melhorando os serviços públicos e aumentando as oportunidades econômicas para a população local [tradução e destaque nosso] (Viotti, 2011b, p. 8).

Dessa forma, a delegação brasileira alegou que os avanços até então alcançados pela MINUSTAH se relacionavam ao fato de se ter aglutinado em algumas estratégias os campos do desenvolvimento social e econômico aos da segurança como questões chaves para o notável êxito da missão em campo. Destarte, o Brasil foi favorável à prorrogação do mandato da MINUSTAH ao considerar que a proposta de redução do contingente 
das tropas para os níveis pré-terremoto seria compatível com os recursos disponíveis para a atuação da operação em campo.

No que se refere ao desempenho futuro da missão no Estado haitiano, o Brasil defendeu a inserção de maiores debates no âmbito do CSNU sobre as perspectivas relacionadas à operação, sinalizando assim, a necessidade de uma reflexão coletiva de determinadas atividades específicas executadas em campo, pois na mediada em que as estratégias evoluíam, as interações entre desenvolvimento e segurança tornar-se-iam um dos elementos-chave de uma paz sustentável (Viotti, 2011b, p. 8).

Desse modo, segundo discursos oficiais do Brasil ${ }^{15}$, dados do Instituto de Pesquisa Econômico Aplicada - IPEA (2013) e da Agência Brasileira de Cooperação (2005) pode-se afirmar que o engajamento brasileiro em seus esforços civil-militares nas operações de paz da ONU contribuiu para a reconstrução do Haiti; assim como, do ponto de vista político, as posições brasileiras no CSNU têm reforçado o debate no âmbito do organismo, assim, percebe-se insistência brasileira em inter-relacionar os aspectos ligados ao desenvolvimento socioeconômico aos do fortalecimento da estabilidade e segurança do Estado haitiano.

\section{Considerações Finais}

A participação brasileira, seja do ponto de vista diplomático, seja em sua atuação pragmática nas operações de paz da ONU no Haiti, se configura como um dos principais casos da atuação brasileira em Estados conturbados por conflitos. Assim, as participações do Brasil nestas operações de paz abrem espaços para linhas reflexivas sobre as tomadas de decisões do Estado brasileiro e suas posições políticas no CSNU. As

\footnotetext{
${ }^{15}$ Vide Lula (2005), Amorim (2005b), Viotti (2011a) e Simões (2011).
}

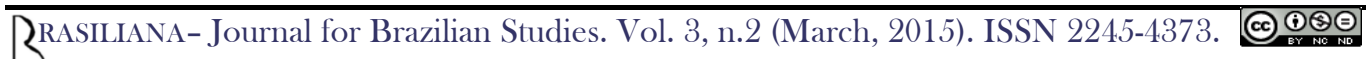


posturas do Brasil sobre as operações de paz no Haiti estiveram pautadas pelos princípios que regem a PEB no meio internacional, tais como: a ênfase no multilateralismo, autodeterminação dos povos, respeito à soberania, ênfase no desenvolvimento das sociedades pós-conflito e repudio as violações aos direitos humanos.

Em relação ao processo de construção da paz haitiana, o Brasil defendeu o processo de estabilização e reconstrução das instituições domésticas do Estado haitiano, contribuiu com a inserção de novas discussões do ponto de vista político-diplomático na esfera do CSNU, como na defesa de interconexão entre os organismos onusianos (CSNU, AGNU e ECOSOC) para a intensificação dos aspectos ligados ao desenvolvimento.

No estabelecimento da primeira missão da ONU no Haiti, a UNMIH (1994), o Brasil se absteve em discordância a utilização do capítulo VII da Carta da ONU. No entanto, no estabelecimento da MINUSTAH (2004), mesmo em face da utilização do capítulo VII o Brasil decidiu apoiar e participar da missão onusiana. Nesse sentido, observa-se uma mudança significativa nas atuações do Brasil nos processos de resolução de conflitos no Haiti.

A leitura permite afirmar que a mudança paradigmática do Brasil em relação ao seu posicionamento favorável no CSNU em resoluções que tragam o estabelecimento de operações baseadas no Capítulo VII no Haiti demonstrou que o Brasil, enquanto ator racional opta por apoiar o estabelecimento destas operações, mesmo que em face do uso da força, ao enxergar nesses mecanismos um dos vetores de sua projeção no meio internacional.

De fato, a oportunidade em ocupar um assento na qualidade de membro não permanente no CSNU durante as discussões sobre as operações de paz no Haiti 
possibilitou ao Brasil a chance de mostrar perante a comunidade internacional o amadurecimento da política externa brasileira perante as questões que tangem a segurança internacional. Essa atuação nos revelou pontos cruciais para o entendimento da postura brasileira no principal organismo multilateral que trata da high politcs das relações internacionais.

\section{Referências Bibliográficas}

Agência Brasileira De Cooperação. Haiti: cooperação para reconstrução e desenvolvimento. Dezembro 2005.2 Disponível [http://www.abc.gov.br/intranet/Sistemas_ABC/siteabc/documentos/ViaABC12.pdf] Acesso em: 05 Jan. 2014.

Albright. [Discurso dos Estados Unidos proferido na 3413 a Sessão do Conselho de Segurança da ONU] In: United Nations. Security Council S/PV3413. The question concerning Haiti. New York: 31 Jul. 1994.

Amorim, Celso. [Discurso do Brasil proferido na 3949aㅗ Sessão do Conselho de Segurança da ONU]. In: United Nations. Security Council S/PV 3949. The question concerning Haiti. New York: 25 Nov. 1998.

- [Discurso do Brasil proferido na Reunião Especial do Conselho de Segurança sobre o Haiti]. In: Brasil. Discursos, palestras e artigos do chanceler Celso Amorim. Brasília: Ministério das Relações Exteriores, 2005b, p. 9-12.

- [Discurso do Brasil proferido na 5110 â Sessão do Conselho de Segurança da ONU]. In: United Nations. Security Council S/PV 5110. The question concerning Haiti. New York: 25 Nov. 2005a.

Araújo, Wemblley L. O papel da MINUSTAH na reconstrução do Estado haitiano através da assistência eleitoral no período 2004-2011. Trabalho de Conclusão de Curso. Bacharelado em Relações Internacionais. Universidade Estadual da Paraíba. 2011. 
- A problemática dos deslocados ambientais haitianos no pós-terremoto: entre dilemas e soluções no Brasil e na República Dominicana. Trabalho apresentado à disciplina Tópicos Especiais em Relações Internacionais: migrações internacionais. Ministrada pela prof. Dra Andrea Pacífico Pacheco. Pós-Graduação em Relações Internacionais. Universidade Estadual da Paraíba, 2013.

Buss, Terry F. Haiti in balance: Why foreign aid has failed and what we can do about it. Terry Buss with Adam Gardener. Washington: Brookings, 2008

Câmara, Irene Pessoa de Lima. Em nome da democracia: OEA e a crise Haitiana (19911994). Brasília: IRB/FUNAG/CEE, 1998.

Cardoso, Afonso José Sena. O Brasil nas operações de paz das Nações Unidas. Brasília: FUNAG, 1998.

Cavallaro, James. Mantendo a paz no Haiti? uma avaliação da missão de estabilização das Nações Unidas no Haiti usando o cumprimento de seu mandato como parâmetro de sucesso. Rio de Janeiro: Centro de Justiça Global, 2005.

Cordeiro, Enio. [Discurso proferido na 4074a Sessão do Conselho de Segurança da ONU]. In: United Nations. Security Council S/PV 4074. The question concerning Haiti. New York: 30 Nov. 1999.

Fonseca Jr., Gelson. O Brasil no Conselho de Segurança 1998-1999. Brasília: FUNAG, 2002.

Gomerssal. [Discurso do Reino Unido proferido na 3413 Segurança da ONU] In: United Nations. Security Counsil S/PV3413. The question concerning Haiti. New York: 31 Jul. 1994.

Guanguia, Wang. [Discurso da China proferido na 4917 ${ }^{\text {a }}$ Sessão do Conselho de Segurança da ONU] In: United Nations. Security Council S/PV4917. The question concerning Haiti. New York: 26 Fev. 2004.

Hagman, Lotta. Lessons Learned Peacebuilding in Haiti. IPA Seminar Report. New York: International Peace Academy, 2002. 
IPEA. Cooperação brasileira para o desenvolvimento Internacional 2010. Brasília: Instituto de Pesquisa Econômica Aplicada - IPEA, 2013.

International Crisis Group. A new chance for Haiti?. ICG Latin America Caribbean. Report $\mathrm{N}^{\circ} 10$, 2004. Disponível em: <http://www.crisisgroup.org/ /media/Files/latinamerica/haiti/10-a-new-chance-for-haiti> Último acesso em 16 Jun. 2013.

Konuzin. [Discurso da Rússia proferido na 4917ª Sessão do Conselho de Segurança da ONU] In: United Nations. Security Council S/PV4917. The question concerning Haiti. New York: 26 Fev. 2004.

Ladsouds. [Discurso da França proferido na 3413 ONU] In: United Nations. Security Counsil S/PV3413. The question concerning Haiti. New York: 31 Jul. 1994.

Lula, Luis Inácio da Silva. [Discurso do Senhor Presidente da República, Luiz Inácio Lula da Silva na Reunião de Cúpula do Conselho de Segurança das Nações Unidas]. 2005. In: Luiz Felipe de Seixas Corrêa (Org.). Brasil e as Nações Unidas. Brasília: FUNAG, 2007, p. $743-746$.

Morrell, James. The Governors Island Accord on Haiti. In: International Policy Report. September $1993 . \quad$ Disponível em: [http://www.haitipolicy.org/archives/Publications\&Commentary/governors.htm]. Acesso em: 10 de Junho. 2014.

Negroponte. [Discurso dos Estados Unidos proferido na 4917ª Sessão do Conselho de Segurança da ONU] In: United Nations. Security Counsil S/PV4917. The question concerning Haiti. New York: 26 Fev. 2004.

Patriota, Antonio de Aguiar. O Conselho de Segurança após a Guerra do Golfo: a articulação de um novo paradigma de segurança coletiva. $2^{\underline{a}}$ ed. Brasília: Fundação Alexandre de Gusmão, 2010.

Sablièle, La. [Discurso da França proferido na 4917å Sessão do Conselho de Segurança da ONU] In: United Nations. Security Council S/PV4917. The question concerning Haiti. New York: 26 Fev. 2004. 
Sardenberg, Ronaldo Mota. Reforma das Nações Unidas: impasses e perspectivas. In: IV Conferência de Política Externa e Política Internacional: o Brasil no mundo que vem aí. Brasília: FUNAG, 2009, p. 43-62.

. O Brasil e as Nações Unidas. Estudos Avançados. vol. 9, n.25, 1995, p. 119-128.

- [Discurso do Brasil proferido na 3413 ONU]. In: United Nations. Security Council S/PV 3413. The question concerning Haiti. New York: 31 Jul. 1994a.

- [Discurso do Brasil proferido na 3430aㅡ Sessão do Conselho de Segurança da ONU]. In: United Nations. Security Council S/PV 3430. The question concerning Haiti. New York: 29 set. 1994 b.

- [Discurso do Brasil proferido na 3282 ${ }^{a}$ Sessão do Conselho de Segurança da ONU]. In: United Nations. Security Council S/PV3272. The question concerning Haiti. New York: 23 Set. 1993.

Simões, Antônio J. Ferreira. [Discurso do Brasil proferido na 6510 a Sessão do Conselho de Segurança da ONU]. In: United Nations. Security Council S/PV 6510. The question concerning Haiti. New York: 6 Abr. 2011.

Thomson. [Discurso do Reino Unido proferido na 4917a Sessão do Conselho de Segurança da ONU] In: United Nations. Security Council S/PV4917. The question concerning Haiti. New York: 26 Fev. 2004.

United Nations. Resoluções do Conselho de Segurança da ONU. Disponível em: [http://www.un.org/en/sc/documents/resolutions/] Acesso em: 12/01/2015.

Uziel, Eduardo. Conselho de Segurança, as operações e manutenção da paz e a inserção do Brasil no mecanismo de segurança coletiva das Nações Unidas. Brasília: FUNAG, 2010.

Valle, Henrique. [Discurso do Brasil proferido na 5090 a Sessão do Conselho de Segurança da ONU]. In: United Nations. Security Council S/PV 5090. The question concerning Haiti. New York: 29 Nov. 2004a. 
Valler Filho, Wladimir. O Brasil e a crise haitiana: a cooperação técnica como instrumento de solidariedade e de ação diplomática. Brasília: FUNAG, 2007.

Viana, Suhayla Mohamed Khalil. A MINUSTAH e a participação brasileira. Dossiê temático. In: Revista Senso Comum. № 1, 2009, p. 22-37

Viegas, Marcelo. A atuação recente do Conselho de Segurança e o Brasil. In: Brigagão, Clovis E Proença Jr, Domício (Org.). O Brasil e a ONU. Brasília: FUNAG, 2008, p. 15-37.

Viotti, Maria Luiza Ribeiro. A Reforma das Nações Unidas. In: In: IV Conferência de Política Externa e Política Internacional: o Brasil no mundo que vem aí. Brasília: FUNAG, 2009, p. 81-98.

- [Discurso do Brasil proferido na 6303a Sessão do Conselho de Segurança da ONU]. In: United Nations. Security Council S/PV 6303. The question concerning Haiti. New York: 28 Abr. 2010a.

- [Discurso do Brasil proferido na 6330 ${ }^{\mathrm{a}}$ Sessão do Conselho de Segurança da ONU]. In: United Nations. Security Council S/PV 6330. The question concerning Haiti. New York: 4 Jun. 2010b.

- [Discurso do Brasil proferido na 6471aㅗ Sessão do Conselho de Segurança da ONU]. In: United Nations. Security Council S/PV 6471. The question concerning Haiti. New York: 20 Jan. 2011a.

- [Discurso do Brasil proferido na 6615 ONU]. In: UNITED NATIONS. Security Council S/PV 6615. The question concerning Haiti. New York: 14 Set. 2011 b.

ZHAOXING. Li. [Discurso da China proferido na 3413 a Sessão do Conselho de Segurança da ONU] In: UNITED NATIONS. Security Council S/PV3413. The question concerning Haiti. New York: 31 Jul. 1994. 